\title{
Resiliensi dan Kejadian Bullying pada Remaja SMP di Demak
}

\author{
Fatimatus Sakdiyah $^{1(\mathrm{CA})}$, Betie Febriana ${ }^{2}$, Wahyu Endang Setyowati ${ }^{3}$ \\ ${ }^{1(\mathrm{CA})}$ Program Studi S1 Keperawatan, Fakultas Ilmu Keperawatan, Universitas Islam Sultan Agung \\ Semarang; fatimasakdiyah39@gmail.com (Corresponding Author) \\ ${ }^{2}$ Program Studi S1 Keperawatan, Fakultas Ilmu Keperawatan, Universitas Islam Sultan Agung Semarang; \\ betie.febriana@gmail.com \\ ${ }^{3}$ Program Studi S1 Keperawatan, Fakultas Ilmu Keperawatan, Universitas Islam Sultan Agung Semarang
}

\begin{abstract}
Adolescence are identical with the search for identity for recognition, in this case teenagers tend do do deviant things like bullying. This type of research is quantitative. The sampling technique in this study used purposive sampling with a total of 147 respondents using the chi square fisher test. The highest resilience there 78 responents with a percentage of 53,1\%, high intimidation category totaling 12 respondents with a percentage of 8,2\%, medium category 19 respondents $12,9 \%$ and low category 116 percentage of $78,9 \%$. There is a relationship between resilience and the incidence of bullying in adolescence with $\mathrm{P}$ value of 0.000 ( $\mathrm{p}$ value $<0.005$ ).
\end{abstract}

Keywords: Incidence of bullying, Adolescents, Resiliency

\begin{abstract}
ABSTRAK
Remaja identik dengan pencarian jati diri untuk sebuah pengakuan, dalam hal ini remaja cenderung melakukan hal menyimpang seperti bullying. Jenis penelitian ini adalah kuantitatif .Tehnik pengambilan sampel pada penelitian ini, peneliti menggunakan metode Purposive Sampling dengan jumlah 147 responden menggunakan Uji Chi Square Fisher. Resiliensi tinggi terdapat 78 responden dengan persentase $53,1 \%$, bullying kategori tinggi sebanyak 12 responden dengan persentase 8,2 \%, kategori sedang 19 responden dengan persentase $12,9 \%$ dan kategori rendah 116 responden dengan presentase $78,9 \%$. Ada hubungan antara resiliensi dan kejadian bullying pada remaja dengan $P$ value 0,000 ( $\mathrm{p}$ value $<0,005)$.
\end{abstract}

Kata Kunci : Kejadian bullying, Remaja, Resiliensi

\section{PENDAHULUAN}

Remaja adalah terjadinya modivikasi kehidupan, dari masa kanak-kanak dan dewasa yang rentan terjadinya masalah psikososial (Steinberg, 2009). Remaja dalam hal ini mengalami fase dimana mereka sedang mencari jati diri untuk tetap eksis di depan teman-teman dan kebanyakan dari mereka tergolong dalam generasi milenial yang membutuhkan sebuah pengakuan. Dalam hal ini remaja cenderung berkelompok atau mempunyai geng terhadap teman sebayanya. Pergaulan remaja dalam tempat yang positif akan menciptakan lingkungan yang positif. Namun jika bergaul dalam kalangan yang salah dapat menyebabkan tindakan menyimpang seperti bullying (Depkes, 2010).

Bullying merupakan perbuatan menyerang, secara terus menerus yang bermaksud untuk menjatuhkan seseorang yang tidak mampu mengontrol dirinya (Olweus, 2004). Tindakan bullying yang 
dilakukan remaja terhadap teman sebayanya seperti mencemooh, menyebarkan gosip, memanggil dengan sebutan nama lain, meyakiti secara verbal maupun tertulis, mengucilkan, mengintimidasi, hingga menyerang secara fisik (Sejiwa, 2008).

Menurut data KPAI prevalensi data perilaku bullying di Indonesia menyebutkan bahwa telah terjadi 161 kasus bullying di Indonesia pada tahun 2018 tepatnya sampai tanggal 30 Mei 2018 yang terdiri dari 41 kasus pelaku kekerasan dari bullying (25,5 persen), 36 kasus anak korban kekerasan dan bullying (22,4 persen) dan 30 kasus korban bullying di sekolah ( 18,7 persen). KPAI mencatat ada 8 kasus korban anak kebijakan selama bulan Januari-April 2019 adapun rinciannya adalah pengeroyokan 3 kasus kekerasan fisik serta terdapat 12 kasus bullying dan 4 kasus perilaku bullying terhadap guru. Febriana (2018) mengatakan bahwa angka terjadinya bullying semakin tinggi dan merupakan jenis kekerasan yang sering muncul di sekolahan.

Beragam dampak yang ditimbulkan oleh bullying sangat memberikan pengaruh negatif terhadap kondisi tubuh. Dalam studinya Elmerbrink, Scielzo, dan Campbell (2015) mendapatkan bahwa bullying dapat berpengaruh terhadap ansietas korban. Menurut Sudibyo (2012) bullying juga dapat menyebabkan korban mengalami psichologycal yang rendah seperti perasaan tidak bahagia, takut sekolah, dan penurunan prestasi akademik.Dalam kondisi selanjutnya ditemukan bahwa remaja mengalami pengasingan diri dari sekolah atau menderita kecemasan sosial (sosial anxiety) bahkan cenderung ingin bunuh diri ( Astuti 2008 dalam Rizqi, 2015).

Resiliensi merupakan suatu fase dimana seseorang yang berada pada keadaan titik terpuruknya tetapi mampu bangkit kembali dan mencoba keluar serta berusaha untuk memecahkan masalahnya dalam situasi tersebut. Menurut penelitian Silvia (2018) jika seorang remaja memiliki resiliensi yang rendah dalam dirinya otomatis remaja itu mudah terpuruk dari dampak bullying. Dalam kondisi selanjutnya ditemukan bahwa remaja mengalami penyendirian diri dari sekolah atau menderita kecemasan sosial (sosial anxiety) bahkan cenderung ingin bunuh diri ( Astuti 2008 dalam Rizqi, 2018). Tetapi jika seorang remaja memiliki resiliensi yang baik dalam dirinya maka akan tidak mudah untuk terpuruk dan mampu bertanggung jawab terhadap masalahnya. Maka itu pertahanan diri sangat dibutuhkan untuk melawan dan melindungi diri dari bullying yang dilakukan oleh teman sebaya agar tubuh tidak mengalami penurunan fungsi gangguan mental.

Hasil studi lapangan pada 9 Mei 2019,peneliti menemukan bahwa 9 dari 10 responden pernah mengalami kejadian bullying. Jenis bullying yang didapat antara lain bullying verbal, fisik dan psikologis. Dari kejadian tersebut kepala Sekolah mengatakan bahwa siswa menjadi malas sekolah bahkan ada yang tidak mau sekolah dan memutuskan untuk keluar. Dari hasil observasi didapatkan bahwa dari 10 responden 9 responden mempunyai cara resiliensi tersendiri saat dibully antara lain 7 siswa membalas atau melawan, 1 siswa diam bahkan menerima dengan lapang dada dan 1 siswa cuek dan mengabaikan. Berdasarkan penelitian tersebut maka peneliti mengadakan penelitian yang berjudul "Hubungan Resiliensi terhadap kejadian bullying pada remaja di Demak. 


\section{METODE}

Penelitian ini merupakan penelitian Deskriptif analitik yang dapat mengetahui hubungan resiliensi terhadap kejadian bullying pada remaja SMP di Demak. Jenis penelitian ini yaitu menggunakan pendekatan Cross Sectional yaitu penelitian dilaksanakan dengan mengukur variabel secara bersamaan dalam waktu satu kali (Sastroasmoro, 2010 ). Responden dalam penelitian ini adalah pelajar siswa SMP yang sedang menempuh pendidikan di SMP Demak.Populasi pada penelitian ini yaitu siswa SMP Kelas VIII sebanyak 200 siswa. Sampel pada penelitan ini adalah siswa SMP sebanyak 147 siswa yang telah dihitung menggunakan rumus, yaitu 93 siswa laki-laki dan 107 siswa perempuan.

Instrumen Pengumpulan data dalam penelitian ini menggunakan kuesioner.Kuesioner ini berupa atau terdiri dari pernyataan-pernyataan untuk mendapatkan informasi dari responden dan di isi oleh responden secara langsung. Kuesioner demografi berisi identitas remaja SMP yang meliputi Jenis Kelamin dan usia. Kuesioner Resiliensi terdiri dari 14 pertanyaan dengan skor: 7: Sangat Setuju, 6: Setuju, 5: Agak Setuju, 4: Netral/biasa saja, 3: Agak Tidak Setuju, 2: Tidak Setuju, 1: Sangat Tidak Setuju. Rentang Skor 14-98. Kuesioner bullying (pelaku) Kejadian Bullying pada Remaja memiliki 9 pertanyaan oleh (Warden, Christie, Cheyne \& Fitzpatrick, (2000); Warden, Cheyne, Christie, Fitzpatrick $\&$ Reid,(2003) ada 9 pertanyaan dengan skor : 2. Sering 1. Kadang-kadang 0. Tidak Pernah. Kuesioner bullying (pelaku) Kejadian Bullying pada Remaja memiliki 9 pertanyaan oleh (Warden, Christie, Cheyne \& Fitzpatrick,(2000); Warden, Cheyne, Christie, Fitzpatrick \& Reid,(2003) ada 9 pertanyaandengan skor : 2. Sering 1 . Kadang-kadang 0. Tidak Pernah.

\section{HASIL DAN PEMBAHASAN}

1. Karakteristik Responden

Tabel 1. Karakteristik Responden siswa SMP di Demak September 2019 (n : 147)

\begin{tabular}{|c|c|c|c|}
\hline No & Karakteristik & Frekwensi & $\%$ \\
\hline \multirow[t]{4}{*}{1.} & Usia & & \\
\hline & - 13 Tahun & 96 & 65,3 \\
\hline & - $\quad 14$ Tahun & 42 & 28,6 \\
\hline & - $\quad 15$ Tahun & 9 & 6,1 \\
\hline 2. & $\begin{array}{l}\text { Jenis Kelamin } \\
-\quad \text { Laki-Laki } \\
-\quad \text { Perempuan }\end{array}$ & $\begin{array}{l}56 \\
91\end{array}$ & $\begin{array}{l}38,1 \\
61,9\end{array}$ \\
\hline
\end{tabular}

Tabel 1 menunjukkan bahwa responden terbanyak pada usia 13 tahun yaitu berjumlah 96 orang (65,3\%). Data dari Plan International And Interational Center For Research On Woman (ICRW) bahwa $84 \%$ anak di Indonesia dengan kisaran usia 12-17 tahun mengalami bullying, angka ini lebih tinggi dibanding negara lain di kawasan Asia. Hasil penelitian oleh Betie Febriana. Anak yang memasuki usia 13-15 tahun adalah masa di mana anak meninggalkan bangku sekolah dasar dan memasuki sekolah lanjutan tingkat pertama (SLTP/SMP). Pada masa ini anak ingin berperan dan dihargai dalam kelompoknya. Menurut anak pada masa ini, perilaku yang baik adalah yang 
menyenangkan dan bisa diterima oleh kelompoknya (teman sebaya). Febriana (2018) mengatakan bahwa angka terjadinya bullying semakin tinggi dan merupakan jenis kekerasan yang sering muncul di sekolahan.

Menurut pendapat peneliti banyaknya responden yang berumur 16 tahun tersebut dikarenakan pada usia 16 tahun rata-rata anak SMA sedang berada pada kelas XI sehingga jumlah responden pada usia tersebut menjadi responden dengan jumlah terbanyak di SMA N 10 Semarang. Remaja umur 16 tahun yang merupakan remaja pertengahan dimana pada masa tersebut sangat membutuhkan teman dan sedang pada masa perkembangan yang ditandai dengan adanya interaksi sosial dengan teman sebaya sehingga tingkat interaksi sosial pada masa remaja cukup tinggi

Selanjutnya berdasarkan Tabel 1 didapatkan hasil bahwa jumlah responden terbanyak dalam penelitian ini adalah berjenis kelamin perempuan sebanyak 91 responden dengan presentase sebesar 61,9\% dari jumlah keseluruhan responden yang diteliti. Dalam penelitian Ann, Anna dan Camilla (2010) pelaku laki-laki cenderung melakukan intimidasi secara fisik, sedangkan pelaku perempuan cenderung melakukan dengan cara halus dan tidak secara langsung, seperti memfitnah, menyebar desas-desus, memanipulasi pertemanan. Menurut penelitian Fatmawati dan Uyun (2016), tentang perbedaan perilaku bullying ditinjau dari jenis kelamin didapatkan hasil bahwa jenis kelamin tidak mempengaruhi terjadinya perilaku bullying. Penelitian ini membuktikan bahwa tidak ada perbedaan perilaku bullying antara laki-laki maupun perempuan. Peneliti berasumsi bahwa remaja perempuan lebih tinggi tingkat bullyingnya dibandingkan remaja laki-laki hal ini terlihat pada hasil penelitian yang menunjukkan bahwa responden dengan jenis kelamin perempuan lebih banyak dibandingkan dengan responden yang berjenis kelamin laki-laki.

2. Resiliensi Remaja

Tabel 2. Tingkat Interaksi Sosial pada siswa SMP di Demak September 2019 (n : 147)

\begin{tabular}{ccc}
\hline Resiliensi Remaja & Frekwensi & \% \\
\hline - Rendah & 5 & 3,4 \\
- Sedang & 64 & 43,5 \\
- Tinggi & 78 & 53,1 \\
\hline
\end{tabular}

Tabel diatas menunjukkan bahwa responden memiliki tingkat resiiensi yang tinggi terbanyak yaitu sebanyak 78 orang $(53,1 \%)$. Hal ini diperkuat oleh penelitian yang dikemukakan oleh Michael, Patrick dan Gerry (2014) Julia, Jenny dkk (2015) dan Steven, George, Ann dkk (2014) mengemukakan bahwa dukungan dari keluarga, teman, sekolah dan lingkungan sangat berpengaruh terhadap ketahanan dan kesehatan mental individu yang mendapatkan intimidasi.

Menurut penelitian Silvia (2018) jika seorang remaja memiliki resiliensi yang rendah dalam dirinya otomatis remaja itu mudah terpuruk dari dampak bullying. Peneliti berasumsi bahwa pada masa remaja seseorang akan cenderung lebih senang berinteraksi dengan orang lain, dan mulai berusaha melakukan penyesuaian-penyesuaian terhadap lingkungannya supaya diterima oleh lingkungannya dan tidak mengalami penolakan dari lingkunganya. Selain itu pada usia remaja seorang 
anak akan lebih banyak berada di lingkungan luar rumah, yaitu disekolah, dengan teman-teman sebaya, sehingga tingkat resiliensi pada remaja sangat tinggi. Maka itu pertahanan diri sangat dibutuhkan untuk melawan dan melindungi diri dari bullying yang dilakukan oleh teman sebaya agar tubuh tidak mengalami penurunan fungsi gangguan mental.

3. Kejadian Bullying (pelaku)

Tabel 3. Kejadian Nomophobia pada siswa SMP di Demak September 2019 (n : 147)

\begin{tabular}{lcc}
\hline Tingkat Nomophobia & Frekwensi & \% \\
\hline - Ringan & 116 & 78,9 \\
- Sedang & 19 & 12,9 \\
- Berat & 12 & 8,2 \\
\hline
\end{tabular}

Tabel 3 diatas menunjukkan bahwa Responden terbanyak mengalami bullying rendah yaitu sebanyak 166 orang (78,9\%). Adapun tindakan bullying yang dilakukan remaja terhadap teman sebayanya seperti mencemooh, menyebarkan gossip, memanggil dengan sebutan nama lain, meyakiti secara verbal maupun tertulis, mengucilkan,mengintimidasi, hingga menyerang secara fisik (Sejiwa, 2008).

Studi terbaru telah menemukan bahwa pelaku bullying selalu dipengaruhi oleh konsekuensi dari perilaku mereka sendiri karena bullying mendistorsi hubungan individu dalam kelompok (Brown et al., 2014 ). Pelaku bullying biasanya dalam melakukan aksinya ada beberapa penyebab yaitu karena sipelaku merasa kesepian sehingga mencari kesibukan dengan cara membully teman-temannya yang dianggap lemah dan tidak punya pertahanan diri dalam membeladirinyasendiri (Inahin, 2012). Akibat dari kejadian bullying itu sendiri membuat individu khusunya bagi pelaku menimbulkan efek negative seperti meningkatnya agresi dan kekerasan fisik( Camadan, 2016 ).

Selain itu, penelitian lain juga menunjukkan bahwa pelaku bullying memiliki gejala psikologis sebagai konsekuensi dari pelaku intimidasi mereka, yaitu kecemasan ( Navarro\& Martinez, 2012). Peneliti berasumsi bahwa tingginya kejadian bullying dikalangan remaja karena kurangnya perhatian dari orang tuanya dan kebanyakan dari mereka membutuhkan sebuah pengakuan dalam mencari jati diri.

4. Hubungan Antara resiliensi dengan kejadian bullying (pelaku)

Tabel 4 Hasil Uji Statistik Chi Square Fisher Hubungan Antara resiliensi dengan kejadian bullying pada remaja smp di demak September 2019 (n: 147)

\begin{tabular}{|c|c|c|c|c|c|c|c|c|}
\hline & & \multirow{2}{*}{\multicolumn{2}{|c|}{ Tingkat }} & \multicolumn{4}{|c|}{ Bullying } & \multirow{3}{*}{ Nilai $p$} \\
\hline & & & & Sed & & Tin & & \\
\hline & & $\mathrm{n}$ & $\%$ & $\mathrm{n}$ & $\%$ & $\mathrm{n}$ & $\%$ & \\
\hline \multirow[t]{4}{*}{ Resiliensi } & Rendah & 1 & - & 4 & $-\%$ & 0 & $-\%$ & 0.000 \\
\hline & Sedang & 49 & - & 5 & $-\%$ & 10 & $-\%$ & \\
\hline & Tinggi & 66 & $-\%$ & 10 & $-\%$ & 2 & $-\%$ & \\
\hline & Total & 116 & $-\%$ & 19 & $-\%$ & 12 & $-\%$ & \\
\hline
\end{tabular}


Tabel 4 diperoleh nilai p 0,000 yang menunjukkan bahwa terdapat hubungan antara resiliensi dan kejadian bullying pada remaja. Menurut penelitian Giane sini dan Brighi (2015) mereka menemukan bahwa ketahanan merupakan variabel yang berharga dan signifikan untuk memhami sifat dari tindakan bullying. Hasil penelitian yang di dapatkan pelaku tidak dapat beradaptasi sehingga menimbulkan berbagai gejala psikologis.

Masten, Coats Worth dan Terzi (2014) mengemukakan bahwa definisi ketahanan menunjukkan bahwa jika seseorang mengakomodasi diri sendiri kekondisi negatif, maka tingkat ketahanannya tinggi. Sedangkan, menurut Masten (2014) menekankan bahwa individu dengan tingkat resiliensi yang tinggi tidak memiliki hambatan perkembangan meskipun terjadi peristiwa traumatis yang mereka hadapi selama hidup mereka. Pelaku cenderung memiliki ketahanan tubuh maupun mental yang kuat, meskipun dalam kehidupannya mereka pernah mengalami trauma yang mendalam tetapi dalam perkembangan dirinya tidak akan berpengaruh terhadap mentalnya meskipun mereka selalu ber akomodasi ke hal negative terhadap seseorang atau korban bullying.

Menurut penelitian Giane sini dan Brighi (2015) menemukan bahwa resiliensi adalah suatu hal yang sangat penting yang harus dimiliki oleh suatu individu. Mereka menemukan bahwa pelaku bullying ingin bersinar dalam teman kelompok sebayanya dengan cara menampilkan perilaku maladaptive dan bermasalah. Pelaku bullying biasanya memiliki daya tahan yang rendah karena mereka menciptakan kelompok teman sebaya yang buruk dan merugikan diri mereka sendiri. Hal ini membuat mereka individu yang maladaptive tentang ketahanan. Karena tidak bisa dipungkiri setiap orang senang diperhatikan dan beberapa orang senang menjadi pusat perhatian, karena ketahanan diri yang lemah dalam menekan ego diri yang ingin selalu tampil menonjol akhirnya timbullah perilaku mal adaptif untuk mencapai tujuan tersebut salah satunya adalah membully.

\section{KESIMPULAN}

Responden terbanyak usia 13 tahun (65,3\%),berjenis kelamin perempuan 91 orang $(61,9 \%)$. Terdapat perlakuan bullying tertinggi sebanyak 12 orang sebagai pelaku () dan resiliensi tertinggi 78 orang (). Dengan menggunakan uji Chi squre Fisher didapatkan p value 0,000 $(<0,05)$, maknanya terdapat hubungan antara resiliensi dengan kejadian bullying pada remaja SMP di Demak.

\section{DAFTAR PUSTAKA}

Astuti, P. R. (2008). Meredam Bullying: 3 cara efektif menanggulangi kekerasan pada anak. Jakarta: PT Grasindo. Jakarta: PT Grasindo.

Back. (2015). Negative emotional experiences. Journal of Personality and Social Psychology, 86, 320333.

Betie, F. (2016). Pengaruh terapi kognitif terhadap harga diri remaja korban bullying. Journal Of Nursing Science, 4 , No 1 .

Cook, C.R., Williams. K.R., Guerra, N., \& Kim, T. (2010). Variability in the prevalence of bullying and victimization: A cross-national and methodological analysis. In S.R. Jimerson, S.M. Swearer, \& D. L. Espelage (Eds). Mahwah, NJ: Erlbaum: The International hand book of school bullying. 
Depkes, P. (2010). Kesehatan Remaja, Problem dan Solusinya. Jakarta, Salemba Medika.

Desminta. (2016). Psikologi perkembangan peserta didik. Bandung , PT Remaja Rosdakarya.

Donat, M., Umla uft, S., Dalbert, C. \& Kamble, S. (2012). Belief in a just world, Teacher Justice, and Bullying Behavior. Agressive Behavior, 38, 185-193.

Elmerbrink, s. (2015). The Impact of social and relational victimization on depression, Anxiety, and Lonelines. Journal of Bullying and Social Aggression.

Games-Guadix, M., Orue, I., Smith, P.K., \& Calvete, E. (2013). Longitudinal and reciprocal relations of cyberbullying with depression, substance use, and problematic internet use among adolescents. Journal of Adolescent Health, 53(446-452).

Gianesini, \& Brighi. (2015). Cyberbullying in the are of digital relationships: The unique role of relisience and emotion regulation on adolescent adjustment. Emerald Group Publish, 19, 1-46.

Hurlock. (2012). psikologi perkembangan. Jakarta: Erlangga. In Jakarta Erlangga.

Kowalski, \& Morgan. (2013). Traditional bullying a protential warning sigb of cyberbullying and traditional bullying. Journal of Adolescent Health, 13-20.

Navarro, Yubero, Larranaga, \& Martinez. (2012). Children's cyberbullying victimization: Association with social anxiety and social competence in a spanish sample. Child Indicators Research, 5, 281295.

Notoatmodjo. (2012). Metodologi Penelitian Kesehatan. In Rineka Cipta.

Nursalam. (2013). Metodologi Penelitian Ilmu Keperawatan. In Salemba Medika. Jakarta: Pendekatan Praktis.

Olweus. (2006). Bullying at schools. In Blacwell Publishing. Australia.

Reivich, K. a. (2002). The Resilience Factor: 7 Es-sential Skills Overcoming Life's Inevitable Obstacles,. New York: Broadway Books.

Rigby, \& Smith. (n.d.). Is school bullying really on the rise. Social Psychology of Education, 14, 441455 .

Rizki. (2016). Pelatihan asertivitas terhadap penurunan kecemasan sosial pada siswa korban bullying. Http://ejournal.umm.ac.id.

Sejiwa. (2008). Mengatasi kekerasan di sekolah dan lingkungan sekitar anak. Jakarta, Grasindo.

Silvia Yuliana. (2018). resiliensi remaja dalam menghadapi perilaku bullying. Jurnal Keperawatan BSI, Vol. V1 No.1 April 2018.

Steinberg, L. (2012). Parenting Adolescents. Recent developments in our understanding of parenting: Bidirectional effects, causal models, and the search for parsimony. In M. H. Bornstein (Ed). New York: Handbook of parenting.

Sugiyono. (2008). Metode Penelitian Kunatitatif Kualitatif dan R\&D. In Alfabeta. Bandung.

Wagnild, G. \& Y. (1993). development and psychometric evaluation of the Resilience scale. Journal of Nursing Measurement 1 (2), 165-178. 